\title{
Chemical characterization of the main products formed through aqueous-phase photonitration of guaiacol
}

\author{
Z. Kitanovski ${ }^{1, *}$, A. $\check{C}_{\text {usak }}^{2}$, I. Grgić ${ }^{1}$, and M. Claeys ${ }^{3}$ \\ ${ }^{1}$ Laboratory for Analytical Chemistry, National Institute of Chemistry, Ljubljana, Slovenia \\ ${ }^{2} \mathrm{EN} \rightarrow$ FIST Center of Excellence, Ljubljana, Slovenia \\ ${ }^{3}$ Department of Pharmaceutical Sciences, University of Antwerp (Campus Drie Eiken), Antwerp, Belgium \\ *now at: Laboratory for Food Chemistry, National Institute of Chemistry, Ljubljana, Slovenia
}

Correspondence to: Z. Kitanovski (zoran.kitanovski@ki.si) and I. Grgić (irena.grgic@ki.si)

Received: 13 March 2014 - Published in Atmos. Meas. Tech. Discuss.: 16 April 2014

Revised: 16 June 2014 - Accepted: 20 June 2014 - Published: 12 August 2014

\begin{abstract}
Guaiacol (2-methoxyphenol) and its derivatives can be emitted into the atmosphere by thermal degradation (i.e., burning) of wood lignins. Due to its volatility, guaiacol is predominantly distributed atmospherically in the gaseous phase. Recent studies have shown the importance of aqueous-phase reactions in addition to the dominant gasphase and heterogeneous reactions of guaiacol, in the formation of secondary organic aerosol (SOA) in the atmosphere. The main objectives of the present study were to chemically characterize the main products of the aqueous-phase photonitration of guaiacol and examine their possible presence in urban atmospheric aerosols. The aqueous-phase reactions were carried out under simulated sunlight and in the presence of hydrogen peroxide and nitrite. The formed guaiacol reaction products were concentrated by solid-phase extraction and then purified with semi-preparative high-performance liquid chromatography (HPLC). The fractionated individual compounds were isolated as pure solids and further analyzed with liquid-state proton, carbon-13 and two-dimensional nuclear magnetic resonance (NMR) spectroscopy, and direct infusion negative ion electrospray ionization tandem mass spectrometry ((-)ESI-MS/MS). The NMR and product ion $\left(\mathrm{MS}^{2}\right)$ spectra were used for unambiguous product structure elucidation. The main products of guaiacol photonitration are 4-nitroguaiacol (4NG), 6-nitroguaiacol (6NG), and 4,6dinitroguaiacol $(4,6 \mathrm{DNG})$. Using the isolated compounds as standards, 4NG and 4,6DNG were unambiguously identified in winter $\mathrm{PM}_{10}$ aerosols from the city of Ljubljana (Slovenia) by means of HPLC/(-)ESI-MS/MS. Owing to the strong absorption of ultraviolet and visible light, 4,6DNG could be an important constituent of atmospheric "brown" carbon, especially in regions affected by biomass burning.
\end{abstract}

\section{Introduction}

Lignin is a biopolymer of woody plant tissue mainly composed of three aromatic alcohols: p-coumaryl, coniferyl, and sinapyl alcohols (Simoneit, 2002). The composition of lignin varies among the major plant classes, i.e., angiosperms and gymnosperms. Angiosperm (hardwood) lignins are derived from products of sinapyl alcohol, while gymnosperm (softwood) lignins mainly contain products of coniferyl alcohol and to a lesser extent sinapyl alcohol products. Grass (Gramineae) lignins mainly contain products of p-coumaryl alcohol (Simoneit, 2002). The process of wood burning causes thermal degradation of wood lignins and formation of various degradation products, such as phenols, aldehydes, acids, ketones or alcohols, which generally preserve the original substituents on the aromatic ring. Thus, hardwood burning produces mainly syringol (2,6-dimethoxyphenol) derivatives and guaiacol (2-methoxyphenol) derivatives to a lesser extent, whereas softwood burning exclusively results in guaiacol derivatives (Simoneit, 2002). When emitted into the atmosphere, guaiacol and its derivatives are predominantly distributed in the gas phase (Schauer et al., 2001; Simpson et al., 2005), due to their relatively high vapor pressures (e.g., 21, 8.1 and $0.45 \mathrm{~Pa}$ for guaiacol, 4-methylguaiacol and syringol, respectively, at $25^{\circ} \mathrm{C}$; Sagebiel and Seiber, 1993). However, measurements of guaiacol, syringol and their analogs in winter fog water from California's Central Valley by Sagebiel and Seiber (1993) indicated that their concentrations are higher than those expected on the basis of their vapor pressures. In other words, the enrichment of methoxyphenols in fog water was usually 3 to 4 times higher than that calculated from Henry's law. These observations were explained 
by the possible role of the dissolved fog-borne chemicals in their solubilization. The total methoxyphenol concentration measured in fog water was in the micromolar range (up to $10 \mu \mathrm{mol} \mathrm{L}^{-1}$ for guaiacol and syringol together). The most abundant compounds among the sixteen methoxyphenols studied were guaiacol, 4-methylguaiacol, and syringol. Finally, fog water was proposed to be a suitable medium for studying methoxyphenols, especially in regions impacted by wood burning (Sagebiel and Seiber, 1993). Therefore, the atmospheric aqueous-phase represents an appropriate medium for studying the reactivity of methoxyphenols, such as guaiacol.

Studies dealing with the aqueous-phase reactivity of methoxyphenols are rather scarce. Chang and Thompson (2010) characterized the colored products of different phenols, catechols, guaiacols and syringols formed by reaction with hydrogen peroxide $\left(\mathrm{H}_{2} \mathrm{O}_{2}\right)$ upon irradiation with ultraviolet (UV) light. The infrared (IR) spectra of syringol reaction products showed a great similarity with those of authentic humic-like substances (HULIS) reported in the literature. In addition, Ofner et al. (2011) recently found that the attenuated total reflectance Fourier transform infrared (ATR-FTIR) spectra of in-smog-chamber-formed secondary organic aerosol (SOA) from catechol and guaiacol under simulated sunlight and ozone $\left(\mathrm{O}_{3}\right)$ exhibit absorptions, which were previously reported for natural HULIS and fulvic acids. Gas-phase and aqueous-phase oxidation of phenolic compounds (including methoxyphenols) leads to formation of colored SOA products (including products of dimerization and oligomerization), which absorb UV/Vis light between 200 and $600 \mathrm{~nm}$ and can contribute to aerosol light-absorbing "brown carbon" (Chang and Thompson, 2010; Ofner et al., 2011). In another study, the aqueous-phase photooxidation of guaiacol and syringol $(100 \mu \mathrm{M})$ in the presence of $\mathrm{H}_{2} \mathrm{O}_{2}$ $(100 \mu \mathrm{M})$ was also found to produce ring-retaining aromatic oxidized products, including dimers and oligomers, via phenoxy radical reactions (Sun et al., 2010). Using a highresolution aerosol mass spectrometer (HR-AMS) the authors found signature ions for guaiacol and syringol dimers in a winter $\mathrm{PM}_{2.5}$ sample collected after a fog event in Fresno, California (USA), and concluded that aqueous-phase reactions of phenolic compounds can contribute to SOA, especially in regions affected by wood combustion. In general, guaiacol and syringol were found to be more reactive towards aqueous oxidation than their substituted analogs. Therefore, they are expected to be the most important products among their analogs towards formation of SOA in the atmosphere (Chang and Thompson, 2010).

Liu et al. (2012) examined the heterogeneous reactivity of selected methoxyphenols (syringaldehyde, vanillic acid, and coniferyl aldehyde) towards nitrate $\left(\mathrm{NO}_{3}\right)$ radicals. They studied the reaction kinetics, proposed reaction pathways and identified the reaction products with gas chromatography time-of-flight mass spectrometry (GC-TOFMS). Recently, the formation of nitro products by gas-phase oxidation of guaiacol under high- $\mathrm{NO}_{\mathrm{x}}$ conditions has also been reported (Yee et al., 2013; Lauraguais et al., 2014). Using GC-FID (flame ionization detection) and GC-MS, two nitroguaiacols, i.e., 4-nitroguaiacol and 3- or 6-nitroguaiacol, have been identified (based on MS spectral library search) as gas-phase oxidation products of guaiacol (Lauraguais et al., 2014). However, to the best of our knowledge, there are no studies on the photonitration of guaiacol in atmospheric waters nor have its nitro-products been unambiguously identified so far.

In the present work, the aqueous-phase products of guaiacol formed under simulated atmospheric conditions were studied. Guaiacol was oxidized by photochemically generated hydroxyl $(\mathrm{OH})$ and nitro $\left(\mathrm{NO}_{2}\right)$ radicals, using a custom-built reactor (Grgić et al., 2010). The main goal was to isolate and identify the main reaction products with semi-preparative high-performance liquid chromatography (HPLC) with UV/Vis detection, nuclear magnetic resonance spectroscopy (NMR), and tandem mass spectrometry (MS/MS). Using the isolated compounds as standards, several guaiacol products were further identified in ambient aerosols by means of HPLC-ESI-MS/MS.

\section{Experimental}

\subsection{Reaction and reagent solutions}

The solvents, reagents and standards used for this study are given in Sect. S1 in the Supplement.

For the aqueous-phase photonitration of guaiacol, a $100 \mathrm{~mL}$ reaction mixture was prepared by mixing $10 \mathrm{~mL}$ of $1.0 \mathrm{mM}$ guaiacol solution, $1 \mathrm{~mL}$ of $100 \mathrm{mM} \mathrm{H}_{2} \mathrm{O}_{2}$ and $1 \mathrm{~mL}$ of $100 \mathrm{mM}$ sodium nitrite in a $100 \mathrm{~mL}$ volumetric flask and diluting it to the mark with a $0.055 \mathrm{mM}$ sulfuric acid solution. This mixture with $\mathrm{pH} 4$ contained the following elements: $0.1 \mathrm{mM}$ guaiacol, $1 \mathrm{mM}$ sodium nitrite and $1 \mathrm{mM} \mathrm{H}_{2} \mathrm{O}_{2}$. It was poured in a $250 \mathrm{~mL}$ clean, round-bottom flask and immediately set for reaction under UV/Vis light, as described below (see Sect. 2.2).

The enzyme catalase and ascorbic acid (vitamin C) were tested as reaction quenchers and introduced into reaction mixture aliquots taken from the bulk reaction mixture at defined time intervals. For that purpose, $0.01 \%$ catalase and $1 \%$ ascorbic acid solutions were freshly prepared in Milli-Q water.

\section{Solutions for the aqueous-phase photonitration of guaiacol at a larger scale (for product isolation and identification)}

Solutions for preparation of 4-nitroguaiacol $(4 N G)$ and 4,6-dinitroguaiacol (4,6DNG)

$0.28 \mathrm{~mL}$ of guaiacol (liquid standard), $2.6 \mathrm{~mL}$ of $30 \%$ hydrogen peroxide solution and $25 \mathrm{~mL}$ of $1.0 \mathrm{M}$ sodium 
nitrite aqueous solution were brought into a $250 \mathrm{~mL}$ volumetric flask. $15 \mathrm{~mL}$ of $92 \mathrm{mM}$ sulfuric acid solution was then added and the mixture was adjusted to volume with Milli-Q water. The final reaction mixture with $\mathrm{pH} 4$ contained the following elements: $10 \mathrm{mM}$ guaiacol, $100 \mathrm{mM}$ sodium nitrite and $100 \mathrm{mM} \mathrm{H}_{2} \mathrm{O}_{2}$. It was poured into a $500 \mathrm{~mL}$ round-bottom flask and immediately set for reaction under UV/Vis light, as described below (see Sect. 2.2). After $9 \mathrm{~h}$ of reaction, the reaction mixture was stored in a refrigerator $\left(2-8^{\circ} \mathrm{C}\right.$, in the dark) overnight without addition of reaction quenchers. The reaction products were extracted the following day.

\section{Solutions for preparation of 6-nitroguaiacol (6NG)}

$0.55 \mathrm{~mL}$ of guaiacol, $1.5 \mathrm{~mL}$ of $30 \%$ hydrogen peroxide solution, $15 \mathrm{~mL}$ of $1.0 \mathrm{M}$ sodium nitrite aqueous solution and $10 \mathrm{~mL}$ of $92 \mathrm{mM}$ sulfuric acid were mixed in a $250 \mathrm{~mL}$ volumetric flask, and the mixture was subsequently adjusted to volume with Milli-Q water. This reaction mixture with $\mathrm{pH} 4$ contained the following elements: $20 \mathrm{mM}$ guaiacol, $60 \mathrm{mM}$ sodium nitrite and $58 \mathrm{mM} \mathrm{H}_{2} \mathrm{O}_{2}$. It was transferred to a $500 \mathrm{~mL}$ round-bottom flask and immediately set for reaction under UV/Vis light (see Sect. 2.2). After $6 \mathrm{~h}$ of reaction, the reaction mixture was stored in a refrigerator (2$8^{\circ} \mathrm{C}$, in the dark) overnight without addition of reaction quenchers. The reaction products were extracted the following day.

\subsection{Experimental setup for studying aqueous-phase reactions}

The experimental setup employed for studying the aqueousphase reactivity of guaiacol (Fig. S1 in the Supplement) consisted of a custom-built reactor and a solar simulator (Grgić et al., 2010). The reactor is a modified rotary evaporator (Rotavap R-210, Büchi, Switzerland) equipped with a thermostatted bath (B-491) and a custom-built low-volume condenser. The custom-built condenser was used to minimize the headspace volume above the reaction solution. The thermostatted bath was used to maintain a constant temperature of $25{ }^{\circ} \mathrm{C}$ during the illumination experiments, while continuous mixing of the reaction solution was achieved by rotation of the vessel at a speed of $50 \mathrm{rpm}$ (revolutions per min). As a source of UV and Vis light, a low-cost solar simulator (L.O.T.-Oriel GmbH \& Co. KG, Germany) equipped with a high-pressure xenon short arc lamp (max. power: $300 \mathrm{~W}$, ozone free) was used. The simulator produces a uniform and collimated output beam of $40 \mathrm{~mm}$ diameter. Its irradiance is minimum 1 sun (equivalent to an irradiance of $1367 \mathrm{~W} \mathrm{~m}^{-2}$ ) at a working distance of $180 \mathrm{~mm}$. The xenon lamp emits continuous radiation in the spectral range 250 $2500 \mathrm{~nm}$, but has a negligible output below $260 \mathrm{~nm}$. For the experiments, an output lamp power of $250 \mathrm{~W}$ was used. The reaction vessels employed for the illumination experiments were made of transparent borosilicate glass (Duran; Schott AG, Germany) with a UV cut-off below $300 \mathrm{~nm}$ and negligible absorption (full transmission) in the region $310-2200 \mathrm{~nm}$. For dark reactions, amber reaction vessels (amber Duran; Schott AG) were used with a light transmission lower than $10 \%$ in the region $300-500 \mathrm{~nm}$.

\subsection{Semi-preparative HPLC purification of the reaction product extract}

An Agilent 1100 Series HPLC system (equipped with a solvent degasser, quaternary pump, autosampler, thermostatted column compartment, UV/Vis diode-array detector (DAD), and an analytical-scale fraction collector (FC)) was used for analytical and semi-preparative HPLC, as well as for HPLC-ESI-MS/MS selected reaction monitoring (SRM) experiments. A ChemStation for LC 3-D systems Rev. B.03.02 software (Agilent Technologies) was used for acquisition and analysis of HPLC-UV/Vis (DAD) data. The method for semi-preparative HPLC purification was initially developed at an analytical scale employing an Atlantis T3 column $(3.0 \times 150 \mathrm{~mm}, 3 \mu \mathrm{m}$ particle size; Waters) with an Atlantis T3 guard column $(3.9 \times 20 \mathrm{~mm}, 3 \mu \mathrm{m}$ particle size; Waters $)$. An isocratic separation of the studied guaiacol nitro-products was achieved by using a mobile phase consisting of an acetonitrile (ACN)/tetrahydrofuran (THF)/water (30/4/66, $v / v / v$ ) mixture containing $5 \mathrm{mM}$ ammonium formate buffer $\mathrm{pH} 3$, at a flow rate of $0.5 \mathrm{~mL} \mathrm{~min}^{-1}$. The injection volume and column temperature were $10 \mu \mathrm{L}$ and $30^{\circ} \mathrm{C}$, respectively. For the semi-preparative method, an Atlantis Prep T3 column $(10 \times 250 \mathrm{~mm}, 5 \mu \mathrm{m}$ particle size; Waters $)$ with an Atlantis Prep T3 guard column $(10 \times 10 \mathrm{~mm}, 5 \mu \mathrm{m}$ particle size; Waters) was used. The chromatographic parameters were the same as for the analytical method, except for the mobile phase flow rate and sample injection volume, which were scaled up to $5.0 \mathrm{~mL} \mathrm{~min}^{-1}$ and $100 \mu \mathrm{L}$, respectively. Moreover, in order to completely elute the highly retained reaction products from the column (i.e., high-molecular weight (HMW) oligomers) the elution strength of the mobile phase was increased towards the end of the chromatographic run (Table S1 in the Supplement).

The concentrated product extract (see Sect. S2 in the Supplement) was used for semi-preparative HPLC purification. The product fractions were collected by an analytical-scale FC (Agilent), equipped with a semi-preparative needle and a 10-funnel tray for collection of large volume peaks. It was triggered for peak collection by the UV/Vis (DAD) signal. The DAD signal set at $345 \mathrm{~nm}$ was used for monitoring and collection of the 4NG and 4,6DNG peaks, while for collection of $6 \mathrm{NG}$ the DAD was set at $300 \mathrm{~nm}$. The peak fractions from multiple injections were collected into the same fraction locations (so-called pooling). After pooling, the organic solvents (ACN and THF) were removed by means of rotary vacuum evaporation (Rotavap R-210, Büchi; bath temperature $35^{\circ} \mathrm{C}$ and vacuum pressure 110 mbar). 


\subsection{NMR analysis}

The dried crystalline products (4NG, 4,6DNG, and $6 \mathrm{NG}$ ) obtained after the final product isolation (see Sect. S3 in the Supplement) were dissolved in deuterated chloroform $\left(\mathrm{CDCl}_{3}\right)$ for liquid-state ${ }^{1} \mathrm{H}-\mathrm{NMR},{ }^{13} \mathrm{C}-\mathrm{NMR}$, and $2 \mathrm{D}-\mathrm{NMR}$ analysis. ${ }^{1} \mathrm{H}-\mathrm{NMR},{ }^{13} \mathrm{C}-\mathrm{NMR}$ and $2 \mathrm{D}-\mathrm{NMR}$ spectra were recorded on a Unity Inova $300 \mathrm{MHz}$ NMR spectrometer (Varian Inc., CA, USA). VNMRJ software (Varian Inc.) was used for processing and analyzing the spectra. For $4 \mathrm{NG}, 6 \mathrm{NG}$ and 4,6DNG ${ }^{1} \mathrm{H}$ spectra, 16, 19 and 68 scans, were acquired, respectively, with a relaxation delay of $10.0 \mathrm{~s}$. For $4 \mathrm{NG}, 6 \mathrm{NG}$ and $4,6 \mathrm{DNG}{ }^{13} \mathrm{C}$ spectra, 847,12544 and 878 scans, respectively, and a relaxation delay of $2.0 \mathrm{~s}$ were used. After NMR analysis the deuterated solvent was evaporated and the dried products were sealed in $10 \mathrm{~mL}$ round-bottom flasks and stored in a refrigerator $\left(2-8^{\circ} \mathrm{C}\right)$, until ESI-MS ${ }^{2}$ and/or HPLC-ESI-MS/MS (SRM) analysis.

\subsection{ESI-MS/MS conditions}

A triple quadrupole - linear ion trap hybrid mass spectrometer, 4000 QTRAP LC/MS/MS System (Applied Biosystems/MDS Sciex, Ontario, Canada) equipped with a TurboIonSpray (TIS) source (a variation of an electrospray ionization (ESI) source) was used for direct infusion ESI$\mathrm{MS}^{2}\left(\mathrm{MS}^{2}\right.$-product ion MS) and HPLC-ESI-MS/MS experiments. A central supply of high-purity nitrogen was used for nebulizer, drying, and collision gas.

For obtaining negative ion ESI-MS ${ }^{2}$ product ion spectra of the deprotonated molecules $[\mathrm{M}-\mathrm{H}]^{-}$of nitroguaiacols, their individual standards $\left(200 \mu \mathrm{g} \mathrm{L}^{-1}\right.$ for $4 \mathrm{NG}$, $1500 \mu \mathrm{g} \mathrm{L}{ }^{-1}$ for $6 \mathrm{NG}$ and $180 \mu \mathrm{g} \mathrm{L}-1$ for $4,6 \mathrm{DNG}$, prepared in a methanol/water $3 / 7(v / v)$ mixture containing $5 \mathrm{mM}$ ammonium formate buffer $\mathrm{pH} 3$ ) were directly infused into the TIS source at a flow rate of $10 \mu \mathrm{L} \mathrm{min}^{-1}$ by using a Harvard 11 plus syringe pump (Harvard Apparatus, Holliston, USA). The following MS parameters were used: $-4500 \mathrm{~V}$ for the TIS capillary voltage, $15 \mathrm{psi}$ for the curtain gas, "high" setting (vacuum: $4.5-5.0 \times 10^{-5}$ Torr) for the collision gas, 15 psi for the nebulizer gas (Gas 1), $-50.0 \mathrm{~V}$ for the declustering potential (DP), and $-5.0 \mathrm{~V}$ for the collision cell exit potential (CXP). In order to obtain summed spectra rich in characteristic product ions, the collision energy (CE) was ramped from $-120 \mathrm{~V}$ to $-5 \mathrm{~V}$ using $1 \mathrm{~V}$ per spectrum step.

The detection of nitroguaiacols was achieved by using negative polarity ESI-MS/MS in the SRM mode. The final optimized values of compound-dependent MS/MS parameters used in the SRM method, such as DP, CE and CXP, are given in Table 1. In the final HPLC-ESI-MS/MS (SRM) method, two characteristic SRM transitions of 4NG, 5NG, $6 \mathrm{NG}$ and 4,6DNG were simultaneously monitored (Table 1), for their unambiguous identification in ambient aerosols. The ESI source parameters were as follows: $-4000 \mathrm{~V}$ for the capillary voltage; 16,50 , and $60 \mathrm{psi}$ for the curtain, nebulizer and auxiliary (Gas 2) gas, respectively; and $550^{\circ} \mathrm{C}$ for the source temperature. The dwell time of the SRM transitions was set to $150 \mathrm{~ms}$.

Analyst 1.5 Software (Applied Biosystems/MDS Analytical Technologies Instruments) was used for acquisition and analysis of the direct infusion ESI-MS ${ }^{2}$ and HPLC-ESIMS/MS (SRM) data.

\subsection{Chromatographic conditions for the HPLC-ESI-MS/MS (SRM) method used for identification of nitroguaiacols in aerosol samples}

The identification of guaiacol nitro-products in ambient aerosols was performed on an Atlantis T3 column $(2.1 \times 150 \mathrm{~mm}, 3 \mu \mathrm{m}$ particle size; Waters $)$ preceded by an Atlantis T3 guard column $(2.1 \times 10 \mathrm{~mm}, 3 \mu \mathrm{m}$ particle size; Waters), using the liquid chromatograph and mass spectrometer described in Sects. 2.3 and 2.5. Two different elution regimes were applied to the separation of the nitroguaiacols. For the first elution regime, an isocratic mobile phase, consisting of a methanol/THF/water $(30 / 15 / 55, v / v / v)$ mixture containing $5 \mathrm{mM}$ ammonium formate buffer $\mathrm{pH} 3$, was used (Elution method I; Kitanovski et al., 2012a). The second regime employed an $\mathrm{ACN} / \mathrm{THF} /$ water $(30 / 4 / 66, v / v / v)$ mixture containing $5 \mathrm{mM}$ ammonium formate buffer $\mathrm{pH} 3$, as mobile phase (Elution method II). For both, a flow rate of $0.2 \mathrm{~mL} \mathrm{~min}^{-1}$, an injection volume of $10 \mu \mathrm{L}$ and a column temperature of $30^{\circ} \mathrm{C}$ were used. For the analysis of $\mathrm{PM}_{10}$ extracts, the mobile phase elution strength was increased after the elution of the targeted analytes, to completely elute highly retained material co-injected on the column. The preparation of standard solutions for the identification of the nitroguaiacols in ambient samples is given in Sect. S4 in the Supplement.

\subsection{Sample collection and preparation}

The winter $\mathrm{PM}_{10}$ samples were collected on quartz fibre filters at an urban background location in the city of Ljubljana, Slovenia (Kitanovski et al., 2012a). Additional information about filter pretreatment and weighing, sample collection and storage as well as sample preparation for analysis has been described elsewhere (Kitanovski et al., 2012a).

\section{Results and discussion}

\subsection{Aqueous-phase photonitration of guaiacol}

For studying the aqueous-phase photonitration of guaiacol, reagent concentrations were initially chosen to closely simulate atmospheric aqueous-phase conditions. To match the acidity of cloud waters the $\mathrm{pH}$ of the aqueous medium was adjusted to 4 (Hindman et al., 1994). The concentration of guaiacol $(0.1 \mathrm{mM})$ in the aqueous medium employed for reaction, however, was much higher than its levels 
Table 1. MS/MS (SRM) parameters for the studied nitroguaiacols.

2-methoxy-4-nitrophenol (4-nitroguaiacol; 4NG)

${ }^{\mathrm{a}}$ Declustering potential, ${ }^{\mathrm{b}}$ Collision energy, ${ }^{\mathrm{c}}$ Collision cell exit potential.

measured in fog water samples $(0.0001-0.001 \mathrm{mM}$; Sagebiel and Seiber, 1993), but it is of the order of the maximum concentrations of the total methoxyphenols measured in the same samples. The $\mathrm{H}_{2} \mathrm{O}_{2}$ and nitrite concentrations employed $(1.0 \mathrm{mM})$ were also higher than their reported ambient values, i.e., $\sim 0.1 \mathrm{mM}$ for $\mathrm{H}_{2} \mathrm{O}_{2}$ in cloud water (Watanabe et al., 2006) and $\sim 0.1 \mathrm{mM}$ for nitrite in fog water (Anastasio and McGregor, 2001). It is noted that in most published studies much higher initial concentrations of the reactants than their ambient ones were used (e.g., Chang and Thompson, 2010; Sun et al., 2010; Ervens et al., 2011). This is due to the low concentrations of the formed products when reagent concentrations typical of atmospheric conditions are used, challenging the sensitivity of the spectroscopic techniques used for product identification and/or quantification (UV/Vis, IR and NMR spectroscopy, and mass spectrometry).

After 3 hours under UV/Vis irradiation, the photonitration of guaiacol $(0.1 \mathrm{mM})$ in the presence of $(1.0 \mathrm{mM}) \mathrm{H}_{2} \mathrm{O}_{2}$ and sodium nitrite, yielded a yellow-colored reaction solution. Owing to the presence of reactive radical species $(\mathrm{OH}$, $\mathrm{NO}_{2}$ ) and unreacted $\mathrm{H}_{2} \mathrm{O}_{2}$ in the reaction solution after irradiation, the unreacted guaiacol was further oxidized and/or nitrated, resulting in a complete decay when the solution was left overnight and under dark conditions. Therefore, efficient quenching of the reaction was indicated for studying the guaiacol photonitration kinetics. For that purpose, three methods were investigated: (a) drying out, (b) adding catalase and (c) ascorbic acid to the aliquots of the reaction mixture. The efficiency of drying vs. addition of catalase was first examined. At defined reaction times, i.e., 30, 60, 90, 120, 150, 180 and $250 \mathrm{~min}$ after exposure to UV/Vis, two $0.5 \mathrm{~mL}$ aliquots of the reaction mixture were withdrawn and transferred to autosampler vials $(2 \mathrm{~mL})$. One of the sample vials was immediately set for evaporation under a gentle stream of nitrogen (at room temperature), while $20 \mu \mathrm{L} 0.01 \%$ aqueous catalase solution was added to the other ones and thoroughly mixed. Drying out $0.5 \mathrm{~mL}$ aqueous reaction mixture took more than half an hour and a characteristic odor of volatilized guaiacol could be sensed during that time. After drying, the solid residue was reconstituted into $0.5 \mathrm{~mL}$ of Milli-Q water. After application of the corresponding quenching method, both sample aliquots were immediately subjected to HPLC analysis, without further waiting in the HPLC autosampler. Characteristic chromatograms of the analyzed reaction mixture aliquots, sampled at $t=0 \mathrm{~min}$, quenched by drying or addition of catalase, are given in Fig. 1.

The enzyme catalase was used to destroy the unreacted amount of $\mathrm{H}_{2} \mathrm{O}_{2}$ and by doing so, to quench the reaction(s) involving $\mathrm{H}_{2} \mathrm{O}_{2}$ (Perri et al., 2009, 2010). From Fig. 1 it can be seen that the guaiacol peak in the chromatogram of the sample aliquot quenched with catalase is similar (by height and area) to that of a guaiacol $0.1 \mathrm{mM}$ aqueous standard. In contrast, the guaiacol peak can be barely detected in the 




Figure 1. Chromatograms of an aqueous standard containing $0.1 \mathrm{mM}$ guaiacol (a) and guaiacol reaction mixture aliquots quenched by addition of catalase (b) or by drying (c), both sampled at $t=0 \mathrm{~min}$. Chromatographic conditions: isocratic elution, $\mathrm{ACN} / \mathrm{THF} /$ water $(30 / 4 / 66, v / v / v)$ mixture containing $5 \mathrm{mM}$ am-

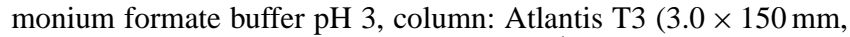
$3 \mu \mathrm{m}$ particle size), flow rate: $0.5 \mathrm{~mL} \mathrm{~min}^{-1}$, column temperature: $30^{\circ} \mathrm{C}$, injection volume: $10 \mu \mathrm{L}$, detection: $\mathrm{UV}(276 \mathrm{~nm})$. The peak eluting at $5.02 \mathrm{~min}$ corresponds to guaiacol.

chromatogram of the sample quenched by solvent evaporation (drying). A consistent absence of the guaiacol peak was observed in the chromatograms of the other reaction mixture aliquots quenched by drying and sampled later during the photonitration reaction. The chromatogram of the guaiacol $0.1 \mathrm{mM}$ aqueous standard after "quenching" by drying showed a negligible guaiacol peak, as well. These experiments demonstrate that reaction quenching by drying is unsuitable for kinetic measurements, since it cannot recover the unreacted amount of guaiacol. This observation is supported by the fact that guaiacol is a small volatile phenolic compound (MW 124) with a vapor pressure of $21 \mathrm{~Pa}$ at $25^{\circ} \mathrm{C}$ (Sagebiel and Seiber, 1993).

The effect of ascorbic acid as reaction quencher was investigated and compared to catalase. A reaction was started as previously described, and two $0.5 \mathrm{~mL}$ aliquots of the reaction mixture were sampled at defined reaction times (see above). The aliquots were transferred into vials containing $50 \mu \mathrm{L} 0.01 \%$ catalase or $50 \mu \mathrm{L} 1 \%$ ascorbic acid solution and subjected to HPLC analysis. For each reaction time, the sample aliquot quenched with catalase was analyzed first ( 2 injections), followed by that quenched with ascorbic acid (2 injections). The time evolution plots are given in Fig. 2.

One obvious difference between both plots in Fig. 2 is the initial concentration (proportional to the peak area) of the reactant (guaiacol) and the main nitration products (4NG, 6NG, and 4,6DNG). When ascorbic acid was used as quencher (Fig. 2b), the peak area of the products was zero, at $t=0 \mathrm{~min}$. In contrast, it was non-zero when catalase was used (Fig. 2a). Although the vials to which catalase was added stood very shortly in the queue before injection and HPLC analysis, the time was sufficient for the reactions of guaiacol oxidation/nitration to proceed and result
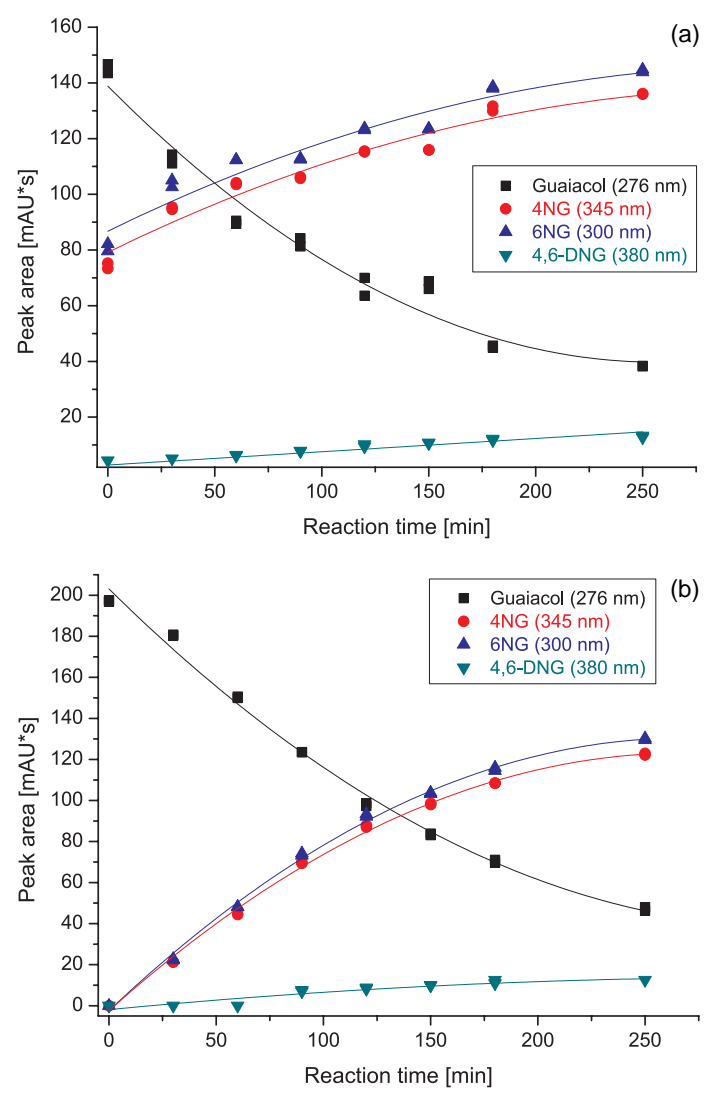

Figure 2. Time evolution of guaiacol, 4-nitroguaiacol (4NG), 6nitroguaiacol (6NG) and 4,6-dinitroguaiacol (4,6DNG) in the presence of $0.1 \mathrm{mM}$ guaiacol, $1.0 \mathrm{mM} \mathrm{H}_{2} \mathrm{O}_{2}$ and $1.0 \mathrm{mM} \mathrm{NaNO}_{2}$ under $\mathrm{UV} / \mathrm{Vis}$ irradiation. Reaction quenched with $0.01 \%$ catalase (a) and $1 \%$ ascorbic acid (b). Chromatographic parameters are the same as in Fig. 1. The used compound specific detection wavelengths are given in parenthesis after the compounds' names.

in products. Another support for this reasoning is the peak area variability for the second consecutive injection of the samples quenched with catalase, which is especially visible for guaiacol (Fig. 2a). For some time points there was up to a $10 \%$ decrease of the guaiacol peak area $(t=120 \mathrm{~min}$, Fig. 2a) in the second analysis compared to the first one, which is above the variability of the analytical method. In contrast, the vials with added ascorbic acid that were analyzed later showed stable peak areas and overall results that favor ascorbic acid as a quencher over catalase.

Ascorbic acid can be converted into dehydroascorbic acid (Fig. S2 in the Supplement), via a two-step oxidation reaction involving an intermediate radical anion, semidehydroascorbic acid, which is a strong acid and a good radical scavenger. Ascorbic acid is an effective scavenger for singlet oxygen (Chou and Khan, 1983; Jung et al., 1995), superoxide radicals and $\mathrm{H}_{2} \mathrm{O}_{2}$, but a weak one for $\mathrm{OH}$ radicals (Wang and Jiao, 2000). In the guaiacol reaction mixture, the concentration of ascorbic acid used was much higher (5 times) than 


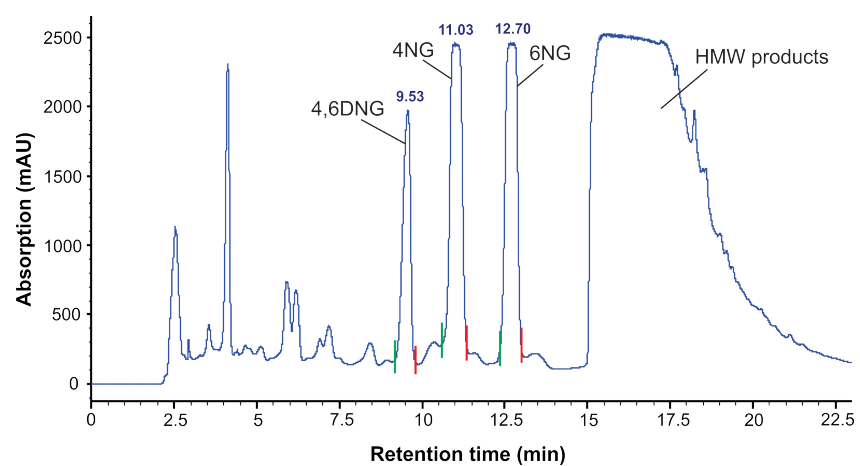

Figure 3. Semi-preparative chromatogram of the guaiacol reaction product extract. Chromatographic conditions: for mobile phase conditions, see Table S1 in the Supplement; column: Atlantis Prep T3 $(10 \times 250 \mathrm{~mm}, 5 \mu \mathrm{m}$ particle size $)$, flow rate: $5 \mathrm{~mL} \mathrm{~min}^{-1}$, column temperature: $30^{\circ} \mathrm{C}$, injection volume: $100 \mu \mathrm{L}$, detection: $\mathrm{UV}$ $(300 \mathrm{~nm})$. Green and red lines intersecting the main peaks represent the times of peak collection start and end, respectively.

the initial concentration of $\mathrm{H}_{2} \mathrm{O}_{2}$ and sodium nitrite. Its efficiency to quench the photonitration of guaiacol is evident from the significant difference between the results shown in Fig. 2a and b. Moreover, ascorbic acid (MW 176) is a very polar compound and does not interfere with the HPLC analysis of the reaction samples, since it elutes in the column void time. In contrast, the use of catalase (a protein of MW $\sim 250000$ ) as quencher caused a gradual increase of the column backpressure during HPLC analysis, most probably owing to the adsorption of the protein on the chromatographic support, which is not removed after regular column cleaning.

\subsection{Characterization of the formed nitroguaiacols}

A semi-preparative chromatogram of the guaiacol product extract is given in Fig. 3. Three main products eluting in the retention time window between 9 and 13 min can be clearly observed. They correspond to the main photonitration products of guaiacol, i.e., 4NG, $6 \mathrm{NG}$, and 4,6DNG. In addition, a huge peak is observed towards the end of the chromatogram, representing compounds which exit the column under the strongest eluting mobile phase composition, used for final column cleaning. This late-eluting peak comprises various light-absorbing, hydrophobic and/or HMW photonitration and oxidation products of guaiacol.

Of the nitroguaiacols, only $4 \mathrm{NG}$ and $5 \mathrm{NG}$ reference standards were commercially available. In the reaction product extract, only $4 \mathrm{NG}$ was identified by its retention time and $\mathrm{UV} /$ Vis (DAD) spectrum. However, the simple matching of retention times and UV/Vis spectra between sample and standard peaks is often not sufficient for unambiguous compound identification in complex samples. Therefore, $4 \mathrm{NG}$ and the other two main (unknown) compounds were first purified with semi-preparative HPLC (Sect. 2.3) and then isolated as pure solids by solid-phase extraction (SPE) (Sect. S3


Figure 4. UV/Vis spectra of the main photonitration products of guaiacol. The spectra were collected during analytical HPLC-UV/Vis (DAD) analysis of the nitroguaiacols. Solvent: $\mathrm{ACN} / \mathrm{THF} /$ water $(30 / 4 / 66, v / v / v)$ mixture containing $5 \mathrm{mM}$ ammonium formate buffer $\mathrm{pH} 3$; and temperature: $30^{\circ} \mathrm{C}$.

in the Supplement). In the following section, we present the UV/Vis, mass and NMR spectra of the obtained pure nitroguaiacols.

\subsubsection{UV/Vis spectra of the nitroguaiacols}

The characteristic UV/Vis spectra of $4 \mathrm{NG}, 6 \mathrm{NG}$ and $4,6 \mathrm{DNG}$ are presented in Fig. 4. They were recorded in the spectral range between 210 and $600 \mathrm{~nm}$. Nitroguaiacols strongly absorb light in the UV and yellow visible region (400-420 nm; Fig. 4), characteristic also for atmospheric "brown" carbon and HULIS (Gelencsér et al., 2003; Chang and Thompson, 2010; Ervens et al., 2011; Ofner et al., 2011; 
Claeys et al., 2012). The absorption bands in the spectra mainly result from $\pi \rightarrow \pi^{*}$ transitions of the aromatic electrons and $n \rightarrow \pi^{*}$ transitions of the electrons from lone pairs of the hydroxy and methoxy groups (Ofner et al., 2011).

The spectrum of $4 \mathrm{NG}$ is very similar to that of 4nitrocatechol, which was reported to be the major constituent of HULIS extracted from $\mathrm{PM}_{2.5}$ collected from the Amazonian rainforest in Rondônia, Brazil (Fig. 7 in Claeys et al., 2012). It shows three strong absorption bands at 212, 242, and $346 \mathrm{~nm}$ (Fig. 4). The spectra of $6 \mathrm{NG}$ and $4,6 \mathrm{DNG}$ are quite different from that of $4 \mathrm{NG}$, with major absorption bands positioned at 222 and $292 \mathrm{~nm}$ for $6 \mathrm{NG}$, and four intense bands at 218, 274, 384, and $426 \mathrm{~nm}$ for 4,6DNG (Fig. 4). In addition to nitroguaiacols, many oxidized/nitrated guaiacol products eluting at the end of the chromatogram (Fig. 3) and corresponding to HMW products are chromophoric with absorptions well extending into the visible region. Guaiacol HMW products (dimers and oligomers) containing conjugated $\pi$-electron systems are important SOA constituents contributing to SOA absorption of visible light (Ervens et al., 2011; Ofner et al., 2011). Therefore, SOA products formed through reactions of oxidation and/or nitration of guaiacol in cloud water can increase the solar light absorption by clouds, thereby influencing the planetary albedo and climate.

\subsubsection{Direct infusion (-)ESI-MS ${ }^{2}$ product ion spectra of the nitroguaiacols}

From this point onward the isolated nitroguaiacols (4NG, $6 \mathrm{NG}$, and 4,6DNG) were used as analytical standards. Figure 5 presents $[\mathrm{M}-\mathrm{H}]^{-} \mathrm{MS}^{2}$ product ion spectra for $4 \mathrm{NG}$ (Fig. 5a), 6NG (Fig. 5b), and 4,6DNG (Fig. 5c). The instrumental conditions used for acquiring the spectra are described in Sect. 2.5. The product ion spectrum of $4 \mathrm{NG}$ (Fig. 5a) contains peaks at $m / z 153$ and 123, corresponding to ions formed by loss of the methyl radical $(15 u)$ from the aromatic methoxy group and a combined loss of the methyl radical and $\mathrm{NO}(15 u+30 u)$ from the deprotonated molecule $(\mathrm{m} / \mathrm{z} 168)$, respectively. In addition, there is a characteristic ion at $m / z 95$, most probably owing to a combined loss of the methyl radical, $\mathrm{NO}$ and $\mathrm{CO}(15 u+30 u+28 u)$ from $[\mathrm{M}-\mathrm{H}]^{-}$(Schmidt et al., 2006; Fig. S3a in the Supplement), as well as an ion at $m / z 46\left(\mathrm{NO}_{2}^{-}\right)$(Fig. 5a).

The product ion spectrum of $6 \mathrm{NG}$ (Fig. 5b) is nearly identical to that of $4 \mathrm{NG}$ (Fig. 5a); it additionally contains three weak peaks at $m / z 125,107$, and 103 . The ion at $m / z 125$ can be explained by a neutral loss of CO from the demethylated product ion at $m / z 153$ (Fig. S3b in the Supplement). After a 1,2-phenyl shift rearrangement (Levsen et al., 2007) it could further lose NO and give the ion at $m / z 95$ (Fig. S3b in the Supplement).

The product ion spectrum of 4,6DNG shows an abundant ion of the deprotonated molecule $(\mathrm{m} / z 213)$, which is very stable and only results in a loss of the methyl radical,
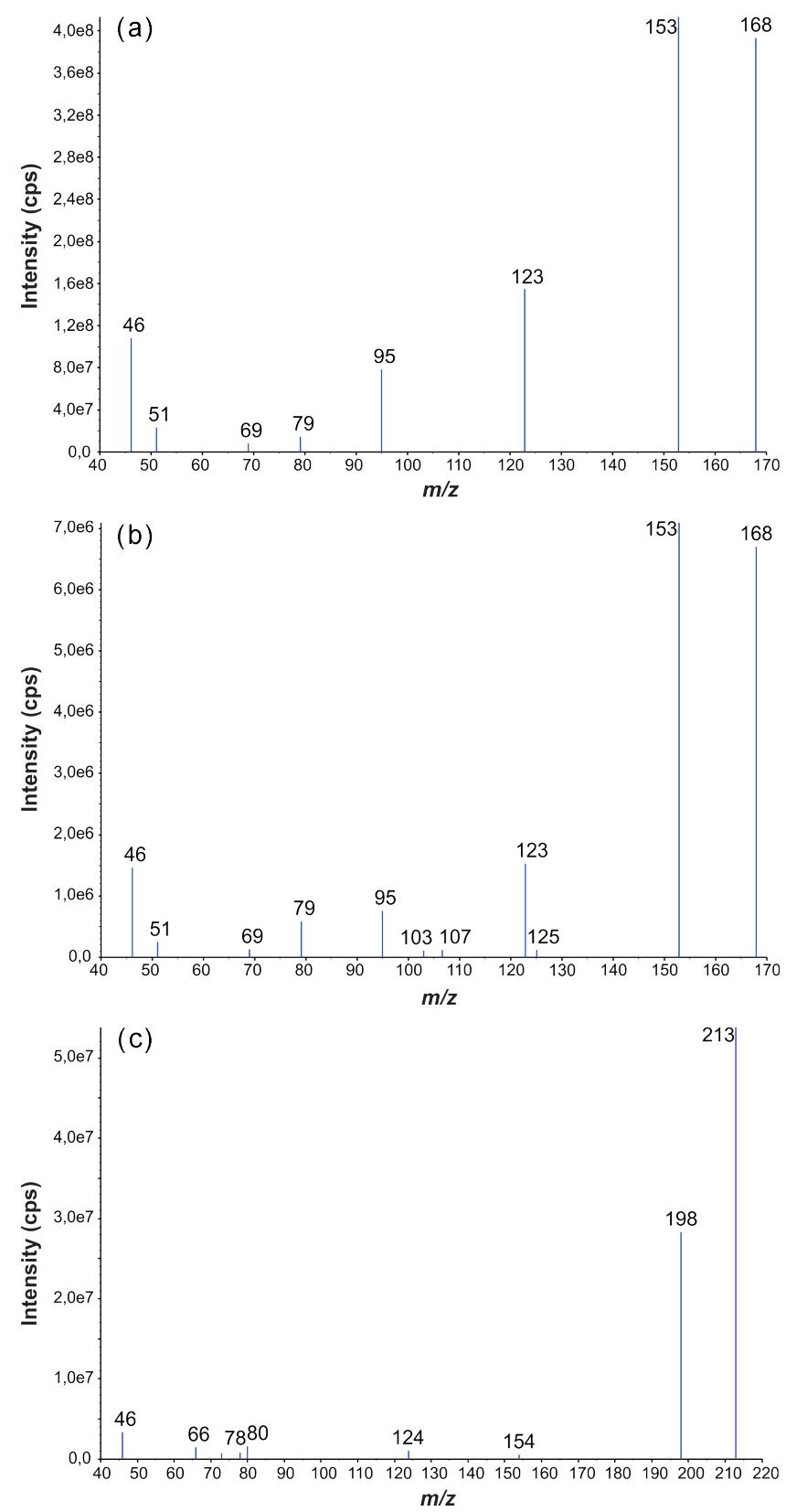

Figure 5. Direct infusion (-)ESI-MS ${ }^{2}$ product ion spectra of $[\mathrm{M}-\mathrm{H}]^{-}$for 4-nitroguaiacol (a), 6-nitroguaiacol (b) and 4,6dinitroguaiacol (c) standards obtained on the 4000 QTRAP instrument.

affording the ion at $m / z 198$ (Fig. 5c). Compared to $4 N G$ and $6 \mathrm{NG}$, the presence of an additional nitro group in the structure of 4,6DNG further decreases the electron density of the aromatic ring and allows the formation of a more stable anion by charge delocalization in the ring (Schmidt et al., 2006). 
Table 2. ${ }^{1} \mathrm{H}$ and ${ }^{13} \mathrm{C}$-NMR data comparison of the reaction-isolated and commercial $4 \mathrm{NG}$ in $\mathrm{CDCl}_{3}$.

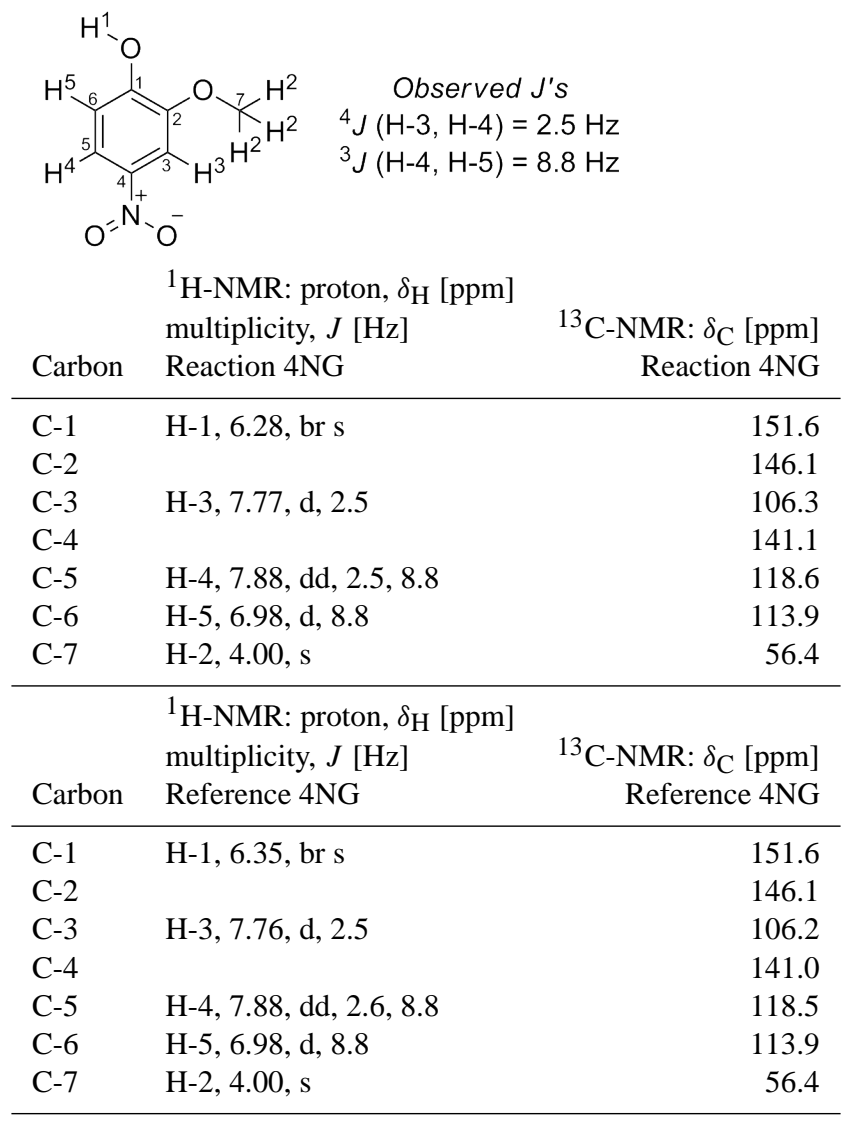

\subsubsection{NMR spectra of the nitroguaiacols}

4-nitroguaiacol was isolated as pale yellow crystals and its structure was unambiguously confirmed by a combination of ${ }^{1} \mathrm{H}-\mathrm{NMR},{ }^{13} \mathrm{C}-\mathrm{NMR}$ and 2D NMR spectroscopy, and comparison of the NMR spectra against a commercially available reference standard. ${ }^{1} \mathrm{H}$ - and ${ }^{13} \mathrm{C}-\mathrm{NMR}$ data of reactionisolated and commercially available $4 \mathrm{NG}$ are compared in Table 2. Analysis of the ${ }^{1} \mathrm{H}-\mathrm{NMR}$ spectrum revealed proton $\mathrm{H}-4\left(\delta_{\mathrm{H}} 7.88 \mathrm{ppm}\right)$, which appears as a doublet of doublets (dd) with corresponding coupling constant $(J)$ values of 2.5 and $8.8 \mathrm{~Hz}$, typical for meta- and ortho-aromatic proton coupling (Table 2). The proton resonance at $7.76 \mathrm{ppm}$ corresponds to H-3, which appears as a doublet (d) with a $J$ value of $2.5 \mathrm{~Hz}$. Based on the $J$ value, proton $\mathrm{H}-3$ occupies the meta-position in respect to $\mathrm{H}-4$. Proton $\mathrm{H}-5$ appears as a doublet with a $J$ value of $8.8 \mathrm{~Hz}$, typical of a vicinal proton coupling in aromatic rings. The proton resonance at $6.28 \mathrm{ppm}$ appeared as a broad singlet (br s) and corresponds to a nonhydrogen bonded phenolic $\mathrm{OH}$ functional group. Finally, the resonance at $4.00 \mathrm{ppm}$ appeared as a singlet (s) which corresponds to a methoxy group. The ${ }^{1} \mathrm{H}$ - and ${ }^{13} \mathrm{C}-\mathrm{NMR}$ data
Table 3. ${ }^{1} \mathrm{H}$ and ${ }^{13} \mathrm{C}-\mathrm{NMR}$ data of $6 \mathrm{NG}$ in $\mathrm{CDCl}_{3}$.



\begin{tabular}{lll} 
Carbon & $\begin{array}{l}{ }^{1} \mathrm{H}-\mathrm{NMR} \text { : proton, } \delta_{\mathrm{H}}[\mathrm{ppm}] \\
\text { multiplicity, } J[\mathrm{~Hz}]\end{array}$ & $\begin{array}{l}{ }^{13} \mathrm{C}-\mathrm{NMR}: \\
\delta_{\mathrm{C}}[\mathrm{ppm}]\end{array}$ \\
\hline $\mathrm{C}-1$ & $\mathrm{H}-1,10.74, \mathrm{~s}$ & 146.3 \\
$\mathrm{C}-2$ & & 150.0 \\
$\mathrm{C}-3$ & $\mathrm{H}-3,7.13, \mathrm{dd}, 1.4,8.1$ & 117.7 \\
$\mathrm{C}-4$ & $\mathrm{H}-4,6.90, \mathrm{dd}, 8.1,8.8$ & 118.9 \\
C-5 & $\mathrm{H}-5,7.68, \mathrm{dd}, 1.4,8.8$ & 116.0 \\
$\mathrm{C}-6$ & & 134.0 \\
$\mathrm{C}-7$ & $\mathrm{H}-2,3.94, \mathrm{~s}$ & 56.7 \\
\hline
\end{tabular}

from the commercially available $4 \mathrm{NG}$ are in agreement with those obtained for the reaction-isolated product (Table 2).

Analysis of ${ }^{13} \mathrm{C}-\mathrm{NMR}$ data disclosed seven distinctive carbon signals. There are two quaternary signals corresponding to oxygenated aromatic $\mathrm{sp}^{2}$ carbons $\mathrm{C}-1$ and $\mathrm{C}-2\left(\delta_{\mathrm{C}} 151.6\right.$ and $146.1 \mathrm{ppm})$ and one quaternary signal from an aromatic $\mathrm{sp}^{2}$ carbon bearing the nitro group, $\mathrm{C}-4\left(\delta_{\mathrm{C}} 141.1 \mathrm{ppm}\right)$. Analysis of ${ }^{13} \mathrm{C}$-NMR and gHSQC (gradient heteronuclear single quantum coherence) spectra disclosed carbons C-5 ( $\delta_{\mathrm{C}}$ $118.6 \mathrm{ppm}), \mathrm{C}-6\left(\delta_{\mathrm{C}} 113.9 \mathrm{ppm}\right)$ and $\mathrm{C}-3\left(\delta_{\mathrm{C}} 106.3 \mathrm{ppm}\right)$. The oxygenated $\mathrm{sp}^{3}$ carbon $\mathrm{C}-7$ bearing a methoxy group displayed a resonance at $56.4 \mathrm{ppm}$. Detailed ${ }^{1} \mathrm{H}-{ }^{13} \mathrm{C}$ gHMBC (gradient heteronuclear multiple bond coherence) and ${ }^{1} \mathrm{H}-{ }^{1} \mathrm{H}$ gCOSY (gradient correlation spectroscopy) correlations are illustrated in Fig. S4 in the Supplement. The phenolic proton appeared as a broad singlet at $6.28 \mathrm{ppm}$ and did not show correlation. In the gHMBC spectrum, the methoxy protons $\mathrm{H}-2\left(\delta_{\mathrm{H}} 4.00 \mathrm{ppm}, \mathrm{s}\right)$ displayed a correlation with C-1 $\left(\delta_{\mathrm{C}}\right.$ $151.6 \mathrm{ppm}), \mathrm{C}-2\left(\delta_{C} 146.1 \mathrm{ppm}\right)$ and $\mathrm{C}-3\left(\delta_{\mathrm{C}} 106.3 \mathrm{ppm}\right)$. The H-3 proton $\left(\delta_{\mathrm{H}} 7.77 \mathrm{ppm}, \mathrm{d}\right)$ showed a correlation with C-1, C-2, C-4 ( $\left.\delta_{\mathrm{C}} 141.1 \mathrm{ppm}\right)$, and C-5 ( $\left.\delta_{\mathrm{C}} 118.6 \mathrm{ppm}\right)$. Furthermore, proton $\mathrm{H}-4\left(\delta_{\mathrm{H}} 7.88 \mathrm{ppm}\right.$, dd) displayed a strong correlation with C-1, C-3, and C-4. Proton $\mathrm{H}-5\left(\delta_{\mathrm{H}} 6.98 \mathrm{ppm}\right.$, d) showed a strong correlation with C-1, C-2 and C-4 (Fig. S4 in the Supplement).

6-nitroguaiacol was isolated as a pale yellow solid and its structure was unambiguously confirmed by ${ }^{1} \mathrm{H}-\mathrm{NMR},{ }^{13} \mathrm{C}$ NMR, and 2D NMR spectroscopy. Based on ${ }^{1} \mathrm{H}-\mathrm{NMR}$ analysis, the phenolic proton of $6 \mathrm{NG}$ resonates at higher frequency $\delta_{\mathrm{H}} 10.74 \mathrm{ppm}(\mathrm{s}, 1 \mathrm{H})$, owing to hydrogen bonding with the adjacent nitro group at the C-6 position (Table 3 ). Additional aromatic and methoxy protons are observed at $\delta_{\mathrm{H}}$ $7.68 \mathrm{ppm}(\mathrm{dd}, J=1.4,8.8 \mathrm{~Hz}, 1 \mathrm{H}), 7.13 \mathrm{ppm}(\mathrm{dd}, J=1.4$, $8.1 \mathrm{~Hz}, 1 \mathrm{H}), 6.90(\mathrm{dd}, J=8.1,8.8 \mathrm{~Hz}, 1 \mathrm{H})$, and $3.94 \mathrm{ppm}$ $(\mathrm{s}, 3 \mathrm{H})$. The proton resonance at $\delta_{\mathrm{H}} 6.90 \mathrm{ppm}$ is split into a doublet of doublets by double ortho-coupling with aromatic 
Table 4. ${ }^{1} \mathrm{H}$ and ${ }^{13} \mathrm{C}-\mathrm{NMR}$ data of $4,6 \mathrm{DNG}$ in $\mathrm{CDCl}_{3}$.

\begin{tabular}{|c|c|c|}
\hline & $\begin{array}{r}\text { Observec } \\
{ }^{4} \mathrm{~J}(\mathrm{H}-3, \mathrm{H}-4)\end{array}$ & $\begin{array}{l}\text { I's } \\
2.6 \mathrm{~Hz}\end{array}$ \\
\hline Carbon & $\begin{array}{l}{ }^{1} \mathrm{H}-\mathrm{NMR} \text { : proton, } \delta_{\mathrm{H}}[\mathrm{ppm}] \\
\text { multiplicity, } J[\mathrm{~Hz}]\end{array}$ & $\begin{array}{l}{ }^{13} \mathrm{C}-\mathrm{NMR}: \\
\delta_{\mathrm{C}}[\mathrm{ppm}]\end{array}$ \\
\hline $\mathrm{C}-1$ & $\mathrm{H}-1,11.18$, br s & 150.6 \\
\hline $\mathrm{C}-2$ & & 150.8 \\
\hline $\mathrm{C}-3$ & H-3, 7.97, d, 2.6 & 111.0 \\
\hline $\mathrm{C}-4$ & & 139.3 \\
\hline $\mathrm{C}-5$ & $\mathrm{H}-4,8.69, \mathrm{~m}$ & 112.6 \\
\hline C-6 & & 132.4 \\
\hline $\mathrm{C}-7$ & $\mathrm{H}-2,4.08, \mathrm{~s}$ & 57.3 \\
\hline
\end{tabular}

$\mathrm{H}-3$ and $\mathrm{H}-5$, thus indicating the pattern of three consecutive aromatic protons. Examination of the ${ }^{1} \mathrm{H}_{-}{ }^{1} \mathrm{H}$ gCOSY spectrum revealed a correlation between $\mathrm{H}-3\left(\delta_{\mathrm{H}} 7.13 \mathrm{ppm}\right)$ and $\mathrm{H}-4\left(\delta_{\mathrm{H}} 6.90 \mathrm{ppm}\right)$ and between $\mathrm{H}-4$ and $\mathrm{H}-5\left(\delta_{\mathrm{H}} 7.68 \mathrm{ppm}\right)$ but displayed no long-range correlation between $\mathrm{H}-3$ and $\mathrm{H}-$ 5. ${ }^{13} \mathrm{C}-\mathrm{NMR}$ analysis displayed seven distinctive ${ }^{13} \mathrm{C}$ signals corresponding to two oxygenated quaternary aromatic $\mathrm{sp}^{2}$ carbons $\left(\delta_{\mathrm{C}} 150.0\right.$ and $\left.146.3 \mathrm{ppm}\right)$, one quaternary aromatic $\mathrm{sp}^{2}$ carbon bearing a nitro functionality $\left(\delta_{\mathrm{C}} 134.0 \mathrm{ppm}\right)$, three aromatic $\mathrm{sp}^{2}$ carbons $\left(\delta_{\mathrm{C}} 118.9,117.7\right.$ and $\left.116.0 \mathrm{ppm}\right)$, and one oxygenated $\mathrm{sp}^{3}$ carbon $\left(\delta_{\mathrm{C}} 56.7 \mathrm{ppm}\right)$.

The detailed ${ }^{1} \mathrm{H}_{-}{ }^{13} \mathrm{C}$ gHMBC, ${ }^{1} \mathrm{H}_{-}{ }^{15} \mathrm{~N}$ gHMBC and ${ }^{1} \mathrm{H}-$ ${ }^{1} \mathrm{H}$ gCOSY correlations are illustrated in Fig. S5 in the Supplement. In the gHMBC spectrum, the phenolic proton $\mathrm{H}-1$ $\left(\delta_{\mathrm{H}} 10.74 \mathrm{ppm}, \mathrm{s}\right)$ displayed a strong correlation with C-1 $\left(\delta_{\mathrm{C}}\right.$ $146.3 \mathrm{ppm}), \mathrm{C}-2\left(\delta_{\mathrm{C}} 150.0 \mathrm{ppm}\right)$, and $\mathrm{C}-6\left(\delta_{\mathrm{C}} 134.0 \mathrm{ppm}\right)$. This data set in combination with the ${ }^{1} \mathrm{H}_{-}{ }^{15} \mathrm{~N}$ gHMBC correlation confirmed that the nitro group is positioned at carbon C-6 adjacent to proton $\mathrm{H}-5\left(\delta_{\mathrm{H}} 7.68 \mathrm{ppm}\right.$, dd $)$ and phenolic proton $\mathrm{H}-1$. Additional HMBC correlations which helped to establish the connectivity for $6 \mathrm{NG}$ are the correlations of the methoxy proton $\mathrm{H}-2\left(\delta_{\mathrm{H}} 3.94 \mathrm{ppm}, \mathrm{s}\right)$ to carbons $\mathrm{C}$ $1, \mathrm{C}-2$ and $\mathrm{C}-3\left(\delta_{\mathrm{C}} 117.7 \mathrm{ppm}\right)$, of the aromatic proton $\mathrm{H}-3$ $\left(\delta_{\mathrm{H}} 7.13 \mathrm{ppm}, \mathrm{dd}\right)$ to carbons $\mathrm{C}-1, \mathrm{C}-2, \mathrm{C}-4\left(\delta_{\mathrm{C}} 118.9 \mathrm{ppm}\right)$ and $\mathrm{C}-5\left(\delta_{\mathrm{C}} 116.0 \mathrm{ppm}\right)$, of the aromatic proton $\mathrm{H}-4\left(\delta_{\mathrm{H}}\right.$ $6.90 \mathrm{ppm}$, dd) to carbons C-2, C-3, C-5 and C-6, and finally of the aromatic proton $\mathrm{H}-5$ to carbons $\mathrm{C}-1, \mathrm{C}-4$, and C- 6 . In addition, the ${ }^{1} \mathrm{H}_{-}{ }^{15} \mathrm{~N}$ gHMBC spectrum displayed a correlation of protons $\mathrm{H}-4$ and $\mathrm{H}-5$ with the nitrogen from the nitro group (Fig. S5 in the Supplement).

4,6-dinitroguaiacol was isolated as a yellow crystalline solid and its structure was unambiguously determined by ${ }^{1} \mathrm{H}-\mathrm{NMR},{ }^{13} \mathrm{C}-\mathrm{NMR}$, and 2-D NMR spectroscopy. The ${ }^{1} \mathrm{H}-$ NMR spectrum of 4,6DNG (Table 4) showed a signal for the phenolic proton resonating at higher frequency $\delta_{\mathrm{H}} 11.18 \mathrm{ppm}$ (br s, $1 \mathrm{H}$ ), thus indicating hydrogen bonding with an adjacent nitro group. Additional aromatic and methoxy protons are observed at $\delta_{\mathrm{H}} 8.69 \mathrm{ppm}$ (multiplet $\left.(\mathrm{m}), 1 \mathrm{H}\right), 7.97 \mathrm{ppm}$ $(\mathrm{d}, J=2.6 \mathrm{~Hz}, 1 \mathrm{H})$, and $4.08 \mathrm{ppm}(\mathrm{s}, 3 \mathrm{H})$. The $\mathrm{H}-3 / \mathrm{H}-4$ coupling constant $\left({ }^{4} \mathrm{~J}=2.6 \mathrm{~Hz}\right)$ is consistent with a metacoupling range typical of aromatic hydrocarbons. The same long-range correlation is observed in the ${ }^{1} \mathrm{H}-{ }^{1} \mathrm{H}$ gCOSY spectrum. In depth analysis of ${ }^{13} \mathrm{C}$ and gHSQC NMR data disclosed seven carbon signals corresponding to two oxygenated quaternary aromatic $\mathrm{sp}^{2}$ carbons $\left(\delta_{\mathrm{C}} 150.8\right.$ and $150.6 \mathrm{ppm}$ ), two quaternary aromatic $\mathrm{sp}^{2}$ carbons bearing a nitro functionality $\left(\delta_{\mathrm{C}} 139.3\right.$ and $\left.132.4 \mathrm{ppm}\right)$, two aromatic $\mathrm{sp}^{2}$ carbons $\left(\delta_{\mathrm{C}} 112.6\right.$ and $\left.111.0 \mathrm{ppm}\right)$, and one oxygenated $\mathrm{sp}^{3}$ carbon $\left(\delta_{\mathrm{C}} 57.3 \mathrm{ppm}\right)$.

The combination of ${ }^{1} \mathrm{H}-\mathrm{NMR},{ }^{13} \mathrm{C}-\mathrm{NMR}$ and $2 \mathrm{DNMR}$ correlation spectroscopy enabled us to assign the NMR signals and establish the nitro substitution pattern in the guaiacol scaffold. Some key ${ }^{1} \mathrm{H}_{-}{ }^{1} \mathrm{H}$ gCOSY and ${ }^{1} \mathrm{H}_{-}{ }^{13} \mathrm{C}$ gHMBC correlations are illustrated in Fig. S6 in the Supplement. The methoxy group protons $\mathrm{H}-2\left(\delta_{\mathrm{H}} 4.08\right.$, s) correlate with $\mathrm{C}-1\left(\delta_{\mathrm{C}} 150.6 \mathrm{ppm}\right), \mathrm{C}-2\left(\delta_{\mathrm{C}} 150.8 \mathrm{ppm}\right)$, and $\mathrm{C}-3\left(\delta_{\mathrm{C}} 111.0 \mathrm{ppm}\right)$. The aromatic proton $\mathrm{H}-3$ correlates with C-2 $\left(\delta_{\mathrm{C}} 150.8 \mathrm{ppm}\right), \mathrm{C}-4\left(\delta_{\mathrm{C}} 139.3 \mathrm{ppm}\right)$ and $\mathrm{C}-5\left(\delta_{\mathrm{C}}\right.$ $112.6 \mathrm{ppm})$, while the aromatic proton $\mathrm{H}-4$ correlates with $\mathrm{C}$ $3\left(\delta_{\mathrm{C}} 111.0 \mathrm{ppm}\right), \mathrm{C}-4\left(\delta_{\mathrm{C}} 139.3 \mathrm{ppm}\right), \mathrm{C}-6\left(\delta_{\mathrm{C}} 132.4 \mathrm{ppm}\right)$, and $\mathrm{C}-1\left(\delta_{\mathrm{C}} 150.6 \mathrm{ppm}\right)$. The phenolic ${ }^{1} \mathrm{H}-\mathrm{NMR}$ shift and correlations of the H-4 proton with C-3, C-4, C- 6 and C-1 indicate a $\mathrm{C}-5$ connection to carbons $\mathrm{C}-4$ and $\mathrm{C}-6$ bearing the nitro group functionality. The deshielding effect of the phenolic ${ }^{1} \mathrm{H}-\mathrm{NMR}$ shift is attributed to hydrogen bonding with the nitro group at C-6.

\subsection{Identification of nitroguaiacols in atmospheric particulate matter}

Isolated nitroguaiacols (6NG and 4,6DNG), as well as commercial $4 \mathrm{NG}$ and $5 \mathrm{NG}$, were used as analytical standards for their HPLC-MS/MS screening in atmospheric $\mathrm{PM}_{10}$ samples. For this purpose, two optimized HPLC-(-)ESI-MS/MS (SRM) methods were used. SRM is a specific and sensitive technique for the mass spectrometric detection and quantification of known analytes, when tandem mass spectrometry in space (i.e., triple quadrupole $(\mathrm{QqQ})$ or quadrupole TOF (QqTOF)) or tandem mass spectrometry in time is being used. In SRM, a precursor ion generated in the ion source is selected by the first mass analyzer (Q1, quadrupole), fragmented by collision-induced dissociation (CID) in the collision cell (q) and one or several product ions derived from it are selected by the second analyzer (Q2, quadrupole or TOF) and transmitted to the detector. The ion transitions used in SRM are based on the well-known fragmentation pattern of the analyte. Therefore, SRM provides analyte-specific detection and is the technique of choice when both quantitative and qualitative data are needed in the analysis of complex samples. Atmospheric aerosol is a complex sample containing thousands of different organic compounds (Goldstein and 
Galbally, 2007). Detection interferences from isobaric compounds (isomers) sharing the same SRM transition can occur, when solely one SRM transition per analyte is used for identification. The use of multiple SRM transitions per analyte together with information about the analyte's chromatographic (retention time) and fragmentation (relative intensities of the SRM traces) properties, will considerably reduce the possibility of reporting false positives (Pizzolato et al., 2007; Picotti and Aebersold, 2012). Therefore, two SRM transitions per analyte were optimized and monitored (Table 1), i.e., $m / z 168 \rightarrow m / z 153$ (SRM1) and $m / z 168$ $\rightarrow m / z 79$ (SRM2) for 4NG, $5 \mathrm{NG}$ and $6 \mathrm{NG}$, and $m / z 213$ $\rightarrow m / z 198$ (SRM1) and $m / z 213 \rightarrow m / z 124$ (SRM2) for 4,6DNG (Figs. 6 and 7). The defined analyte SRM traces should be similar in shape and peak on equal retention times (or completely "coelute") in the chromatogram (Picotti and Aebersold, 2012). Only if these preconditions are satisfied, their relative difference (i.e., SRM1 / SRM2; calculated from peak areas) can be measured and used as an additional identification marker in conjunction with the analyte's retention time (Pizzolato et al., 2007).

The SRM chromatograms presented in Fig. 6 were obtained by using elution method I (Sect. 2.6). The chromatograms of nitroguaiacol standards (Fig. 6a-d) were compared with that of a winter $\mathrm{PM}_{10}$ sample from Ljubljana (Slovenia, Fig. 6e). Based on the retention time $\left(t_{\mathrm{R}}\right)$ match, three nitroguaiacols can be identified in the sample, i.e., 4NG, 6NG, and 4,6DNG (Fig. 6 and Table 5). However, the calculation of SRM1 / SRM2 peak area ratios for each compound in the standard and sample chromatograms revealed a false positive identification of $6 \mathrm{NG}$ made solely by $t_{\mathrm{R}}$ matching of the peaks (Table 5). The calculated SRM1 / SRM2 ratios for $6 \mathrm{NG}$ differ significantly between standard and sample (7.4 vs. 88.7), indicating the presence of an isobaric compound in the sample eluting at the same $t_{\mathrm{R}}$ as $6 \mathrm{NG}$. This claim was further supported by employing a second LC-MS/MS elution method, which provided a significantly different chromatographic selectivity with regard to 6NG (Fig. 7). SRM chromatograms for the same nitroguaiacol standards and sample obtained by using elution method II (Sect. 2.6) are given in Fig. 7a-e. Note the change of the elution order for the nitroguaiacol positional isomers ( $4 \mathrm{NG}, 5 \mathrm{NG}$, and $6 \mathrm{NG}$ ) by only substituting methanol by acetonitrile in the mobile phase (Fig. 6 vs. 7). The elution orders were $6 \mathrm{NG} \rightarrow 5 \mathrm{NG} \rightarrow 4 \mathrm{NG}$ (Fig. $6 \mathrm{~b}-$ d) and $5 \mathrm{NG} \rightarrow 4 \mathrm{NG} \rightarrow 6 \mathrm{NG}$ (Fig. 7b-d) when LC-MS/MS elution method I and II were employed, respectively. Under the conditions of the second method, the $6 \mathrm{NG}$ peak elutes last and is not detected in the winter $\mathrm{PM}_{10}$ sample (Fig. 7b vs. 7e). Like in the previous analysis (Table 5), only $4 \mathrm{NG}$ and 4,6DNG were unambiguously identified in the sample based on retention time match and SRM1 / SRM2 ratios (Table 6). Another observation is that the SRM1/SRM2 ratios for the nitroguaiacol standards (and sample) were almost the same for the two elution methods (Table 5 vs. 6).

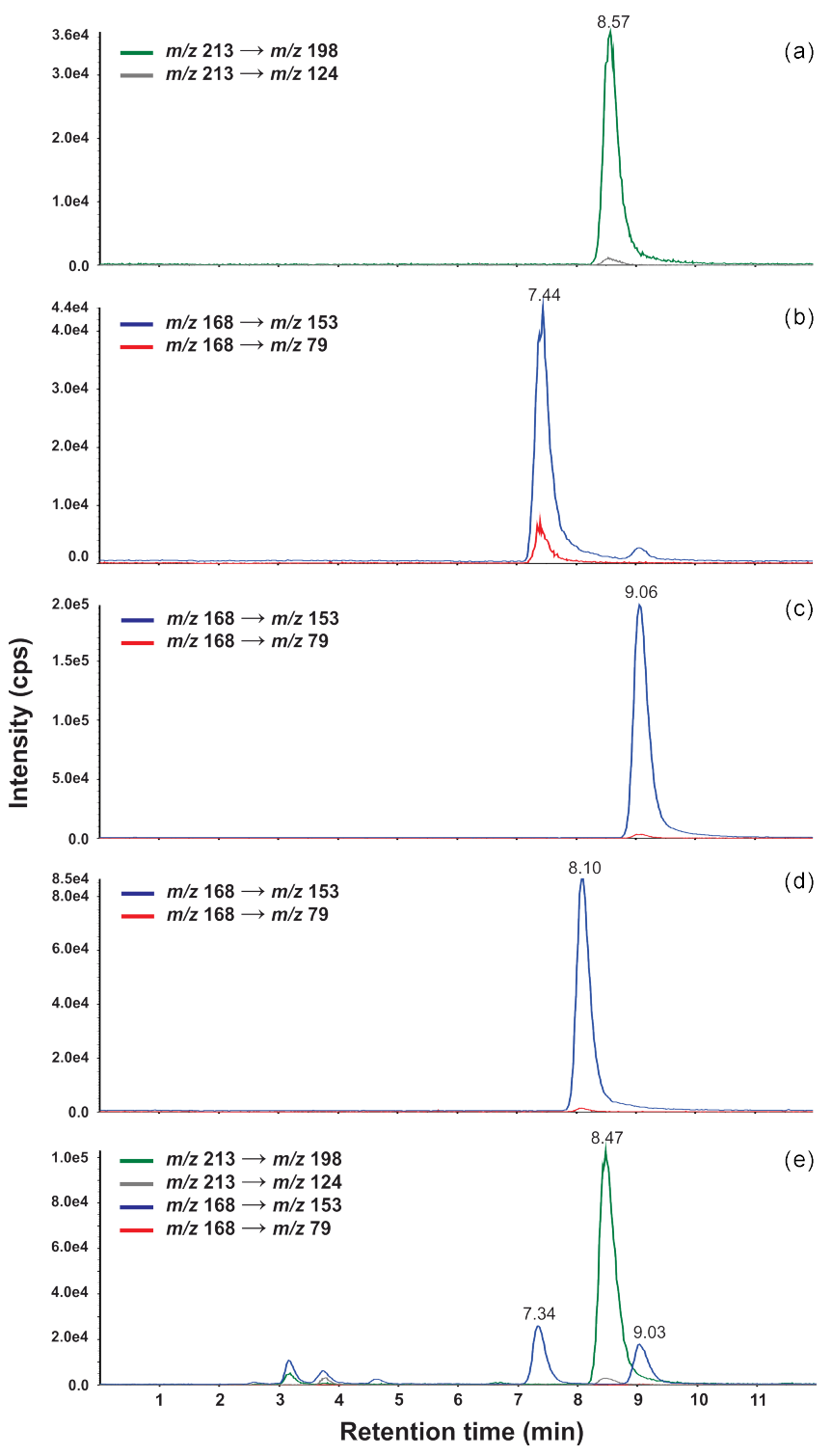

Figure 6. SRM chromatograms for the standards of 4,6DNG $\left(270 \mu \mathrm{gL}^{-1}, \quad\right.$ diluted $\left.1: 100\right) \quad$ (a), $6 \mathrm{NG} \quad\left(1130 \mu \mathrm{g} \mathrm{L}^{-1}\right)$

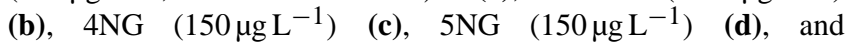
$\mathrm{PM}_{10}$ sample $(23 / 12 / 10)$ (e). Chromatographic conditions: Atlantis T3 column $(2.1 \times 150 \mathrm{~mm}, 3 \mu \mathrm{m}$ particle size $)$; methanol $/ \mathrm{THF} /$ water $=30 / 15 / 55 \quad(v / v / v)$ mixture containing $5 \mathrm{mM}$ ammonium formate buffer $\mathrm{pH} 3$; flow rate: $0.2 \mathrm{~mL} \mathrm{~min}^{-1}$; column temperature: $30^{\circ} \mathrm{C}$; injection volume: $10 \mu \mathrm{L}$; and detection: MS/MS (SRM).

One might conclude that this is an expected result, since the same compound-dependent MS/MS (SRM) parameters were used in both methods and the fragmentation of analyte ions will be identical and independent of the mobile phase conditions. This is however only true for small molecules having a single charge-bearing site in ESI (Wang et al., 2010) such as for those in this study (i.e., a phenolic $\mathrm{OH}$ group). In other cases, the analyte's fragmentation pattern depends 
Table 5. SRM1 / SRM2 ratios obtained by using LC-MS/MS elution method I.

\begin{tabular}{lllll}
\hline \multicolumn{5}{c}{ SRM1 / SRM2 ratio } \\
\hline Analytes & $\begin{array}{l}\text { Standard } \\
( \pm \mathrm{SD} ; n=3)\end{array}$ & $\begin{array}{l}23 / 12 / 10 \\
\mathrm{PM}_{10} \text { sample }\end{array}$ & $\begin{array}{l}\text { Identified } \\
\text { (by SRM1 / SRM2) }\end{array}$ & $\begin{array}{l}t_{\mathrm{R}} \text { match } \\
(\text { SD vs. sample) }\end{array}$ \\
\hline 4-nitroguaiacol & $59.4( \pm 1.5)$ & 50.0 & Yes & Yes \\
5-nitroguaiacol & $68.3( \pm 4.8)$ & not detected & No & No \\
6-nitroguaiacol & $7.4( \pm 0.1)$ & 88.7 & No & Yes \\
4,6-dinitroguaiacol & $33.6( \pm 0.9)$ & 33.1 & Yes & Yes \\
\hline
\end{tabular}

Table 6. SRM1 / SRM2 ratios obtained by using the LC-MS/MS elution method II.

\begin{tabular}{lllll}
\hline \multicolumn{5}{c}{ SRM1 / SRM2 ratio } \\
\hline Analytes & $\begin{array}{l}\text { Standard } \\
( \pm \mathrm{SD} ; n=3)\end{array}$ & $\begin{array}{l}23 / 12 / 10 \\
\mathrm{PM}_{10} \text { sample }\end{array}$ & $\begin{array}{l}\text { Identified } \\
\text { (by SRM1 / SRM2) }\end{array}$ & $\begin{array}{l}t_{\mathrm{R}} \text { match } \\
(\text { SD vs. sample) }\end{array}$ \\
\hline 4-nitroguaiacol & $61.1( \pm 0.9)$ & 58.7 & Yes & Yes \\
5-nitroguaiacol & $68.8( \pm 3.8)$ & not detected & No & No \\
6-nitroguaiacol & $7.2( \pm 0.1)$ & not detected & No & No \\
4,6-dinitroguaiacol & $28.0( \pm 0.6)$ & 32.9 & Yes & Yes \\
Peak at $t_{\mathrm{R}}=6.84$ min & - & 89.2 & - & -
\end{tabular}

on the mobile phase composition, $\mathrm{pH}$ and ionic strength, especially for larger molecules, such as peptides and proteins (Wang et al., 2010, and references therein).

$4 \mathrm{NG}$ was recently reported to be one of the major nitroproducts of guaiacol gas-phase oxidation under high- $\mathrm{NO}_{\mathrm{x}}$ conditions (Lauraguais et al., 2014). We have previously identified and quantified $4 \mathrm{NG}$ in the same set of winter $\mathrm{PM}_{10}$ samples from Ljubljana (Kitanovski et al., 2012a). The concentration of 4,6DNG, however, was only estimated in three winter PM $_{10}$ samples (from the same set of samples as in Kitanovski et al., 2012a), by using an external standard calibration and LC-MS/MS elution method I, which was already validated (Kitanovski et al., 2012a), but not for the determination of 4,6DNG. Its concentration was determined in the present study and ranged from 0.15 to $0.8 \mathrm{ng} \mathrm{m}^{-3}$, which is in the same order of magnitude as the winter particulate concentrations of methyl-nitrophenols and nitrosalicylic acids (Kitanovski et al., 2012a). To the best of our knowledge, our study is the first report on the identification of $4,6 \mathrm{DNG}$ in ambient aerosols. In a very recent study, the formation of $4,6 \mathrm{DNG}$ in a smog chamber through heterogeneous reaction of particulate surface-bound vanillic acid or coniferaldehyde with gas-phase $\mathrm{NO}_{3}$ radicals has been reported (Liu et al., 2012). In addition to its heterogeneous production, gas-phase and aqueous-phase nitration of guaiacol (and nitroguaiacols) can thus also be significant formation pathways of 4,6DNG in the atmosphere. Additional studies are warranted to link its atmospheric production with recent biomass burning events.

The peak eluting at $t_{\mathrm{R}}=6.84 \mathrm{~min}$ in Fig. 7e corresponds to the nitroguaiacol isobaric compound eluting at the same $t_{\mathrm{R}}$ as $6 \mathrm{NG}$ in Fig. 6e $\left(t_{\mathrm{R}}=7.34 \mathrm{~min}\right)$. It is the same compound as previously detected in winter $\mathrm{PM}_{10}$ samples from Maribor and Ljubljana (Peak at $t_{\mathrm{R}}=9.26 \mathrm{~min}$ in Fig. $5 \mathrm{c}$ and its $\mathrm{MS}^{2}$ spectrum in Fig. 7b from Kitanovski et al., 2012b, and peak 10 in Fig. 3 from Kitanovski et al., 2012a) and speculated to be $6 \mathrm{NG}$. The present study rules out that this compound is $6 \mathrm{NG}$. The only possible nitroguaiacol isomer which was neither available commercially nor could be obtained by photonitration of guaiacol is 3-nitroguaiacol (2methoxy-3-nitrophenol). However, previous studies on nitration pathways of electron-rich aromatics (including guaiacol) report the formation of derivatives with the nitro group bound on the aromatic ring in ortho- or para-positions with respect to the phenolic OH group (Sobolev, 1961; Dwyer and Holzapfel, 1998), thus rendering the formation of 3-nitroguaiacol quite unlikely. Another possible compound corresponding to the unknown peak at $t_{\mathrm{R}}=6.84 \mathrm{~min}$ (Fig. 7e) could be an isomeric nitro-methoxyphenol, where the methoxy and hydroxy groups are in para-position to each other (4-hydroxyanisole moiety); in this respect, 2-nitro-4methoxyphenol (or 3-nitro-4-hydroxyanisole) can be a reasonable candidate (Robinson and Smith, 1926), since its precursor, anisole (methoxybenzene), is emitted into the atmosphere by natural and anthropogenic combustion of hydrocarbons.

\section{Conclusions}

The research presented was mainly focused on the isolation and structure elucidation of the main guaiacol products obtained by photonitration in the aqueous phase. Furthermore, 


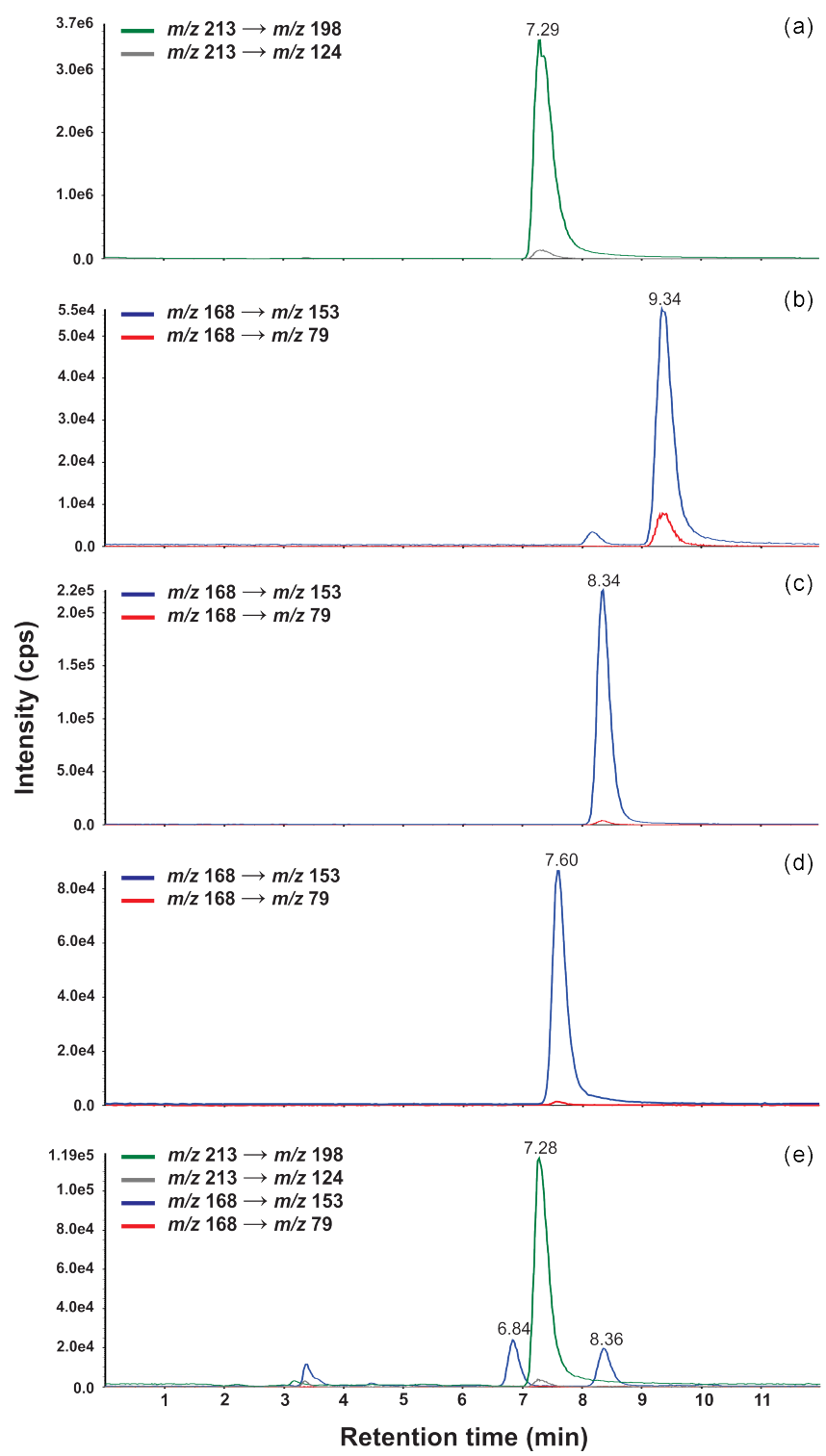

Figure 7. SRM chromatograms for the standards of $4,6 \mathrm{DNG}$

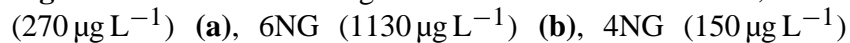
(c), 5NG $\left(150 \mu \mathrm{gL}^{-1}\right)$ (d), and $\mathrm{PM}_{10}$ sample (23/12/10) (e). Chromatographic conditions: Atlantis T3 column $(2.1 \times 150 \mathrm{~mm}$, $3 \mu \mathrm{m}$ particle size); $\mathrm{ACN} / \mathrm{THF} /$ water $=30 / 4 / 66(v / v / v)$ mixture containing $5 \mathrm{mM}$ ammonium formate buffer $\mathrm{pH} 3$; flow rate: $0.2 \mathrm{~mL} \mathrm{~min}^{-1}$; column temperature: $30^{\circ} \mathrm{C}$; injection volume: $10 \mu \mathrm{L}$; and detection: MS/MS (SRM).

their possible presence in urban atmospheric aerosols was also examined. Initially, we examined the efficiency of different quenching methods applied to the samples withdrawn from the reaction medium at defined reaction times. The addition of ascorbic acid to the reaction samples was shown to provide the desired quenching of the reaction(s), compared to the addition of catalase or quenching by drying out the sample. Analytical and semi-preparative HPLC-UV/Vis methods were optimized for studying the composition of the formed guaiacol SOA and purifying the main guaiacol nitroproducts, respectively. The products in the purified fractions were further isolated as pure solids by means of SPE and finally characterized by UV/Vis and NMR spectroscopy, and MS. The main photonitration products of guaiacol, i.e., 4NG, $6 \mathrm{NG}$ and 4,6DNG, were screened for their presence in winter urban aerosols by using an optimized HPLC-(-)ESI-MS /MS (SRM) method. In order to reduce the possibility of reporting false positive identifications, two characteristic SRM transitions per compound were monitored during the analysis. 4NG and 4,6DNG were unambiguously identified in the aerosol samples. The aerosol concentration of 4,6DNG was found to be substantial and was estimated to be comparable to those of methyl-nitrophenols and nitrosalicylic acids. Owing to the strong absorption of UV and visible light (with wavelengths up to $500 \mathrm{~nm}$ ), 4,6DNG could be an important constituent of atmospheric "brown" carbon, especially in regions affected by biomass burning. Furthermore, the presence of two nitro groups in the structure increases its toxicity towards humans and non-human biota.

\section{The Supplement related to this article is available online at doi:10.5194/amt-7-2457-2014-supplement.}

Acknowledgements. This work was supported by the Slovenian Research Agency (Contract Nos. P1-0034-0104 and BI-BE/1112-F-012). The authors would like to thank mag. Tanja Bolte from the Environmental Agency of Republic of Slovenia for providing the $\mathrm{PM}_{10}$ samples. We also would like to express our gratitude to Aleksandar Gaćeša from the Slovenian NMR Center (National Institute of Chemistry, Ljubljana) for his generous help during the NMR measurements.

Edited by: Y. Iinuma

\section{References}

Anastasio, C. and McGregor, K. G.: Chemistry of fog waters in California's Central Valley: 1. In situ photoformation of hydroxyl radical and singlet molecular oxygen, Atmos. Environ., 35, 1079-1089, 2001.

Chang, J. L. and Thompson, J. E.: Characterization of colored products formed during irradiation of aqueous solutions containing $\mathrm{H}_{2} \mathrm{O}_{2}$ and phenolic compounds, Atmos. Environ., 44, 541-551, 2010.

Chou, P. T. and Khan, A. U.: L-ascorbic acid quenching of singlet delta molecular oxygen in aqueous media: Generalized antioxidant property of vitamin C, Biochem. Biophys. Res. Commun., 115, 932-937, 1983.

Claeys, M., Vermeylen, R., Yasmeen, F., Gómez-González, Y., Chi, X., Maenhaut, W., Mészáros, T., and Salma, I.: Chemical characterisation of humic-like substances from urban, rural and tropical biomass burning environments using liquid chromatography with $\mathrm{UV} /$ vis photodiode array detection and electrospray ionisation mass spectrometry, Environ. Chem., 9, 273-284, 2012. 
Dwyer, C. L. and Holzapfel, C. W.: The nitration of electron-rich aromatics, Tetrahedron, 54, 7843-7848, 1998.

Ervens, B., Turpin, B. J., and Weber, R. J.: Secondary organic aerosol formation in cloud droplets and aqueous particles (aqSOA): a review of laboratory, field and model studies, Atmos. Chem. Phys., 11, 11069-11102, doi:10.5194/acp-1111069-2011, 2011.

Gelencsér, A., Hoffer, A., Kiss, G., Tombácz, E., Kurdi, R., and Bencze, L.: In-situ formation of light-absorbing organic matter in cloud water, J. Atmos. Chem., 45, 25-33, 2003.

Goldstein, A. H. and Galbally, I. E.: Known and unexplored organic constituents in the Earth's atmosphere, Environ. Sci. Technol., 41, 1514-1521, 2007.

Grgić, I., Nieto-Gligorovski, L., Net, S., Temime-Roussel, B., Gligorovski, S., and Wortham, H.: Light induced multiphase chemistry of gas-phase ozone on aqueous pyruvic and oxalic acids, Phys. Chem. Chem. Phys., 12, 698-707, 2010.

Hindman, E. E., Campbell, M. A., and Borys, R. D.: A ten-winter record of cloud-droplet physical and chemical properties at a mountaintop site in Colorado, J. Appl. Meteorol., 33, 797-807, 1994.

Jung, M. Y., Kim, S. K., and Kim, S. Y.: Riboflavin-sensitized photooxidation of ascorbic acid: kinetics and amino acid effects, Food Chem., 53, 397-403, 1995.

Kitanovski, Z., Grgić, I., Vermeylen, R., Claeys, M., and Maenhaut, W.: Liquid chromatography tandem mass spectrometry method for characterization of monoaromatic nitro-compounds in atmospheric particulate matter, J. Chromatogr. A, 1268, 35-43, 2012a.

Kitanovski, Z., Grgić, I., Yasmeen, F., Claeys, M., and Čusak, A.: Development of a liquid chromatographic method based on ultraviolet-visible and electrospray ionization mass spectrometric detection for the identification of nitrocatechols and related tracers in biomass burning atmospheric organic aerosol, Rapid Commun. Mass Sp., 26, 793-804, 2012b.

Lauraguais, A., Coeur-Tourneur, C., Cassez, A., Deboudt, K., Fourmentin, M., and Choël, M.: Atmospheric reactivity of hydroxyl radicals with guaiacol (2-methoxyphenol), a biomass burning emitted compound: Secondary organic aerosol formation and gas-phase oxidation products, Atmos. Environ., 86, 155-163, 2014.

Levsen, K., Schiebel, H. M., Terlouw, J. K., Jobst, K. J., Elend, M., Preiß, A., Thiele, H., and Ingendoh, A.: Even-electron ions: a systematic study of the neutral species lost in the dissociation of quasi-molecular ions, J. Mass Spectrom., 42, 1024-1044, 2007.

Liu, Ch., Zhang, P., Wang, Y., Yang, B., and Shu, J.: Heterogeneous reactions of particulate methoxyphenols with $\mathrm{NO}_{3}$ radicals: Kinetics, products, and mechanisms, Environ. Sci. Technol., 46, 13262-13269, 2012.

Ofner, J., Krüger, H.-U., Grothe, H., Schmitt-Kopplin, P., Whitmore, K., and Zetzsch, C.: Physico-chemical characterization of SOA derived from catechol and guaiacol - a model substance for the aromatic fraction of atmospheric HULIS, Atmos. Chem. Phys., 11, 1-15, doi:10.5194/acp-11-1-2011, 2011.

Perri, M. J., Seitzinger, S., and Turpin, B. J.: Secondary organic aerosol production from aqueous photooxidation of glycolaldehyde: Laboratory experiments, Atmos. Environ., 43, 1487-1497, 2009.

Perri, M. J., Lim, Y. B., Seitzinger, S. P., and Turpin, B. J.: Organosulfates from glycolaldehyde in aqueous aerosols and clouds: Laboratory studies, Atmos. Environ., 44, 2658-2664, 2010.

Picotti, P. and Aebersold, R.: Selected reaction monitoring-based proteomics: workflows, potential, pitfalls and future directions, Nat. Methods, 9, 555-566, 2012.

Pizzolato, T. M., de Alda, M. J. L., and Barceló, D.: LC-based analysis of drugs of abuse and their metabolites in urine, TrACTrend. Anal. Chem., 26, 609-624, 2007.

Robinson, R. and Smith, J. C.: LI.-The relative directive powers of groups of the form RO and RR'N in aromatic substitution. Part III. The nitration of some $p$-alkyloxyanisoles, J. Chem. Soc., 129, 392-401, 1926.

Sagebiel, J. C. and Seiber, J. N.: Studies on the occurrence and distribution of wood smoke marker compounds in foggy atmospheres, Environ. Toxicol. Chem., 12, 813-822, 1993.

Schauer, J. J., Kleeman, M. J., Cass, G. R., and Simoneit, B. R. T.: Measurement of emissions from air pollution sources. 3. $\mathrm{C}_{1}-\mathrm{C}_{29}$ organic compounds from fireplace combustion of wood, Environ. Sci. Technol., 35, 1716-1728, 2001.

Schmidt, A.-C., Herzschuh, R., Matysik, F.-M., and Engewald, W.: Investigation of the ionisation and fragmentation behaviour of different nitroaromatic compounds occuring as polar metabolites of explosives using electrospray ionisation tandem mass spectrometry, Rapid Commun. Mass Sp., 20, 2293-2302, 2006.

Simoneit, B. R. T.: Biomass burning - a review of organic tracers for smoke from incomplete combustion, Appl. Geochem., 17, 129$162,2002$.

Simpson, C. D., Paulsen, M., Dills, R. L., Liu, L.-J. S., and Kalman, D. A.: Determination of methoxyphenols in ambient atmospheric particulate matter: Tracers for wood combustion, Environ. Sci. Technol., 39, 631-637, 2005.

Sobolev, I.: Lignin model compounds. Nitric acid oxidation of 4methylguaiacol, J. Org. Chem., 26, 5080-5085, 1961.

Sun, Y. L., Zhang, Q., Anastasio, C., and Sun, J.: Insights into secondary organic aerosol formed via aqueous-phase reactions of phenolic compounds based on high resolution mass spectrometry, Atmos. Chem. Phys., 10, 4809-4822, doi:10.5194/acp-104809-2010, 2010.

Wang, S. Y. and Jiao, H.: Scavenging capacity of berry crops on superoxide radicals, hydrogen peroxide, hydroxyl radicals, and singlet oxygen, J. Agric. Food Chem., 48, 5677-5684, 2000.

Wang, J., Aubry, A., Bolgar, M. S., Gu, H., Olah, T. V., Arnold, M., and Jemal, M.: Effect of mobile phase $\mathrm{pH}$, aqueous-organic ratio, and buffer concentration on electrospray ionization tandem mass spectrometric fragmentation patterns: implications in liquid chromatography/tandem mass spectrometric bioanalysis, Rapid Commun. Mass Sp., 24, 3221-3229, 2010.

Watanabe, K., Takebe, Y., Sode, N., Igarashi, Y., Takahashi, H., and Dokiya, Y.: Fog and rain water chemistry at Mt. Fuji: A case study during the September 2002 campaign, Atmos. Res., 82, 652-662, 2006.

Yee, L. D., Kautzman, K. E., Loza, C. L., Schilling, K. A., Coggon, M. M., Chhabra, P. S., Chan, M. N., Chan, A. W. H., Hersey, S. P., Crounse, J. D., Wennberg, P. O., Flagan, R. C., and Seinfeld, J. H.: Secondary organic aerosol formation from biomass burning intermediates: phenol and methoxyphenols, Atmos. Chem. Phys., 13, 8019-8043, doi:10.5194/acp-13-8019-2013, 2013. 